\title{
Analysis Approach to Identify Factors Influence Digital Learning Technology Adoption and Utilization in Developing Countries
}

\author{
https://doi.org/10.3991/ijet.v13i02.7399 \\ Abubaker Kashada( $\left.{ }^{\bowtie}\right)$, Hongguang Li \\ Beijing University of Chemical Technology, Beijing, China \\ $2012420020 @ m a i l$.buct.edu.cn \\ Osama Koshadah \\ Zawia University, Zawia, Libya
}

\begin{abstract}
The Internet has given learners the ability to learn anytime and anywhere at their own pace facilitated by interactive and adaptive software. Digital learning technology is more than just providing students with a laptop. Digital learning requires a combination of technology, digital content, and instruction. This study aims to identify and observe the impact and mediation of top management support in relation to the successful adoption of digital learning technologies in developing countries. A questionnaire was designed and distributed to rate the successful adoption and utilization of digital learning technologies in developing countries and data was analyzed using structural equation modeling. This study provides empirical evidence and explains many complex factors, such as user awareness, perceived usefulness, perceived ease of use, and information communication technology infrastructure, in the context of top management support to facilitate the effective utilization of a digital learning technology. Mediating the top management support between adoption of a digital learning technology and user awareness, perceived usefulness, and perceived ease of use provides clear and crucial evidence to support the effective adoption of a digital learning technology.
\end{abstract}

Keywords - digital learning technology, e-learning, developing countries, emerging learning technologies adoption success

\section{Introduction}

Digital learning technology (DLT) is defined as any type of learning that facilitated by instructional practice or by technology that makes effective use of technology and gives students some element of control over place, time, path and/or pace. Digital learning technology provides a unique opportunity to enhance the quality of education in a cost-effective manner. DLT encompasses intelligent tutoring, game-based learning, accessing digital content, collaborating locally and globally, assessment and reporting online, and Massively Open Online Courses (MOOCs) etc. [1]. 
DLT improves the level of students' participation during the learning process and allows them to learn at their own pace and organize the order topics for the study plan, thereby resulting in more independent learning. However, the globalization of the DLT is paralleled with the dramatic developing in the using of the internet and other technologies as supported tools [2].

The adoption and utilization of digital technologies in the educational system and the internet have provided an unprecedented opportunity to create advanced education around the globe [3]. Developing countries are categorized as such because their rank in the United Nations Development Program (UNDP) Human Development Index is low. There is a growing need for developing countries to adopt and utilize emerging technologies in learning. However, developing countries are slow to adopt new technologies, particularly with regard to DLT. There is also a significant need for educational institutions in developing countries to upgrade traditional education to improve learning processes [4]. The developing countries are a region which has suffered both financially, economically, and technologically compared to the rest of the globe and the process of DLT adoption facing challenges and obstacles in almost all the developing countries and is rather still at initial stages and slow growing in some cases due to a number of factors such as, personal, organizational, and technological challenges. However, in such countries, adoption and utilization of DLT in educational institutions are at an early stage [5].

The adoption and utilization of educational technology in the developing countries faced many difficulties in the educational system and it does not always lead directly proportional increases in student learning outcomes, therefore, it is very important to investigate and understand the critical success factors in order to optimize student outcomes [6].

This research examines various reasons for the success/failure of DLT adoption processes in Libyan organizations. Critical factors that contribute to developing countries not utilizing DLT successfully can be identified by investigating the proposed research questions and by addressing factors that lead to the success/failure of such systems.

\subsection{Research problem and question}

The research problem is related to the rapid development of information systems and technology. In particular, we focus on whether developing countries, such as Libya, can take advantage of such developments. The study identifies and examines the reasons why DLT fail in Libyan educational institutions and the following question summarize the research problem.

What factors are responsible for DLT failures in countries with less developed economies, such as Libya? 


\section{$2 \quad$ Literature review}

Recently, researchers attempted to identify challenges that hinder effective implementation of DLT in developing countries and have conducted qualitative and quantitative analyses focusing on e-learning integration in developing countries to pinpoint factors that influence the successful adoption and utilization of DLT. On one hand, each study considered a certain case to investigate this phenomenon. On the other hand, each developing country has apparent differences in its economic state, the level of education, and culture. Therefore, further investigation and analysis are required, especially in countries where little or no research has been conducted.

Top management support (TMS) is related to the apparent level of general support offered by top management. Ragu-Nathan et al. [7] defined top management support as the degree to which senior executives understand the significance of information technology/information system functions and are involved in the system activities. Loonam et al. [8] reported that top managers play a vital role in supporting information technology systems. Top management support involves providing the essential authority required for project success. With top management support, more institutions adopt and implement DLT successfully [9].

User awareness (UA), i.e., user perception of a DLT adoption process, is an important factor [10]. The adoption and utilization of new technology in an educational institution can face challenges that are related to user awareness [11]. In most cases, users without proper knowledge or awareness of the new technology or system being adopted will have a negative attitude toward the successful adoption and utilization process; consequently, they are less likely to fully welcome the new strategy. However, users with effective awareness will perceive the system or technology positively, which facilitates easy, convenient, and smooth implementation [12].

Davis [13] defined perceived usefulness (PU), as "the degree to which people believe that the use of a particular system would enhance their job performance." Perceived usefulness is a significant factor affecting the acceptance of an information technology in an institution in a developing country. Redfern [14] defined perceived usefulness as the level of faith a person has in a particular system that has been implemented to increase productivity and improve work performance.

Perceived ease of use (PEOU), refers to the degree to which people believe that the use of a particular system would be effort free [13]. In this context, effort relates to how easy or difficult it is to learn to use the new system.

Information and Communication Technology (ICT) is a major component of information technology management and considered in a beginning stage in the developing countries particularly in the field of the learning process and teaching. However, many such institutions have not benefited from ICT investments [15]. Rai [16] identified information communication technology infrastructure as a key agent of the business value that a firm can realize from its collaborative innovation relationships.

The growing use of ICT and the Internet in the developing countries by the individuals, government, and non-government has changed several things from the traditional to the digital world [17]. Libya as one of the developing countries tries to benefit from using ICT in all sectors, particularly in education sector. there is lack of pro- 
grams and studies that measure the successful adoption and utilization digital learning systems to improve the educational process in Libyan [18].

Akinnuwesi [19] investigated factors that influenced the intent to use biometric technology in developing countries and found that perceived ease of use was important. In addition, they found that user awareness was also influential. However, the study concluded that perceived usefulness had no impact on the intent to adopt the biometric technology.

Ali [20] explored the utilization and adoption of information technology in nontechnologically advanced countries. They pointed out that some approaches related to technology acceptance and usage in advanced technological cultures may be applicable to developing cultures. They also emphasized that acceptance and usage could be improved by effective end-user training and top management support. In addition, they revealed that the success implementation of information technology systems is strongly influenced by the opposition of users to the perceived change that is related to a new technology implementation and adoption.

Sife [21] discussed the challenges for integrating learning technologies in higher learning institutions with examples from Tanzania as developing countries. The study explored the challenges and obstacles for integrating learning technologies in higher learning institutions as, awareness, administrative support, technical support, and staff training and development. The study is argued that universities in developing countries should adopt learning technologies to improve both teaching and learning processes. Technical and cost issues should be taken into account for each specific technology when integrating ICTs in teaching and learning process.

Khan [15] presented a comprehensive review of international articles relating to barriers encountered when introducing ICT into classrooms in Bangladesh as developing country. The study revealed that ICT infrastructure and staff training are among the factors influencing the success of educational technology systems. A study by Elzawi [9] investigated the factors affecting Internet use by staff members, how the internet affects research and teaching, and the level of Libyan research into IT development and implementation. The study found that the training programs and technical skills play a significant role in the successful adoption of ICTs. Tarus [1] discussed the challenges experienced by Kenyan public universities in the implementation of elearning systems. The study findings revealed that e-learning comes with some challenges that must be addressed by Kenyan public universities before successful implementation can be realized and recommended possible solutions towards successful implementation of the digital learning system.

Our study aims to explore the factors that affect the adoption and utilization of DLT in Libyan public universities in the learning process. To achieve the main objectives and based on the results of the reviews on literature regarding adoption theories and the literature, the study maps a path model, which includes the critical factors to be considered for successful adoption and utilization of DLT in the educational sector in Libya. Based on the literature and enlightened the foundation in building a mediation path model for TMS between DLT and PEOU, PU, and UA as discussed previously, we proposed the following hypotheses. 
H1. TMS mediates the link between PU and DLT.

H2. TMS mediates the link between PEOU and DLT.

H3. TMS mediates the link between UA and the use of a DLT.

H4. TMS is significantly influenced by and directly linked to DLT.

H5. ICT infrastructure is significantly influenced by and directly linked to DLT.

\section{$3 \quad$ Methodology}

We designed a questionnaire to rate the successful adoption and utilization of DLT in developing countries and the rating scale was determined by reviewing the literature to identify scales used in previous studies. The questionnaire was distributed to 210 participants at Zawia University in Libyan. All participants were full-time students and participation was optional, and no identifiable private information was collected. The sample was selected randomly from different study levels. The response rate was 91.4\% (192 out of 210). The rating scale was Strongly Disagree (1), Disagree (2), Neutral (3), Agree (4), and Strongly Agree (5) and the obtained data were processed and analyzed using the Statistical Package for Social Software and Linear Structural Relations.

\section{$4 \quad$ Analysis and discussion}

\subsection{Descriptive statistics}

Construct validity is defined as the degree to which a test measures what it claims or purports to be measuring. Internal consistency reliability is defined as "a measure of how well the items on the test measure the same construct or idea" [22]. Both construct validity and internal consistency were examined using Cronbach's alpha (.797). Cronbach's alpha typically ranges between 0 and 1. As Cronbach's alpha approaches 1.0, the internal consistency of the items in the scale increases [22]. Variables were checked to ensure that they met the assumptions of normal distribution and multicollinearity. Multicollinearity refers to the linear relationship between two or more variables, including the orthogonality among the variables [23]. This relationship is also referred to as collinearity or ill-conditioning. Multicollinearity was assessed by examining the Variance Inflation Factor (VIF) and tolerance. Here, tolerance is a measure of collinearity and is always greater than or equal to 1 . No multicollinearity issues were observed, and the assumption about reasonable independence among predictor variables was satisfied (Table 1).

Table 2 summarizes that the simple correlation $R$ value $=0.602$, which indicates a good degree of correlation, and the $R^{2}$ value $=0.363$, which indicates the extent of the total variation in the adoption of DLT, indicating that the dependent variable adoption of the DLT was influenced by $36.3 \%$ by the independent variables TMS, UA, PU, PEOU, and ICT Infrastructure. 
Table 3 shows the ANOVA results. As can be seen, the probability level of significance is 0.000 . Therefore, the probability value is much less than 0.05 . Top management support, user awareness, perceived usefulness, perceived ease of use, and information communication technology infrastructure simultaneously showed a significant effect on the adoption of the DLT.

Table 4 shows the obtained coefficient values. As can be seen, significant values were obtained for top management support (0.000) and ICT infrastructure (0.001) and no significant values were obtained for user awareness $(0.112)$, perceived usefulness (0.065), and perceived ease of use (0.960).

Table 1. Tolerance and VIF

\begin{tabular}{|c|c|c|c|}
\hline \multicolumn{2}{|c|}{ Coefficients $^{\mathbf{a}}$} \\
\hline \multirow{2}{*}{ Model } & \multicolumn{2}{c|}{ Collinearity Statistics } \\
\cline { 2 - 4 } & \multirow{2}{*}{ TMS } & 0.679 & 1.473 \\
\hline \multirow{4}{*}{1} & UA & 0.615 & 1.625 \\
\cline { 2 - 4 } & PU & 0.654 & 1.529 \\
\cline { 2 - 4 } & PEOU & 0.784 & 1.276 \\
\cline { 2 - 4 } & ICT Infrastructure & 0.625 & 1.601 \\
\cline { 2 - 4 } & & & \\
\hline
\end{tabular}

a. Dependent Variable: Adoption of DLT

Table 2. Model summary

\begin{tabular}{|c|c|c|c|c|}
\hline Model & $\mathbf{R}$ & $\boldsymbol{R}^{\mathbf{2}}$ & Adjusted $\boldsymbol{R}^{\mathbf{2}}$ & Std. estimate error \\
\hline 1 & $0.602^{\mathrm{a}}$ & 0.363 & 0.346 & 0.54311 \\
\hline
\end{tabular}

a. Predictors: (Constant), TMS, UA, PU, PEOU ICT Infrastructure.

Table 3. ANOVA results

\begin{tabular}{|c|l|c|c|c|c|c|}
\hline \multicolumn{7}{|c|}{ ANOVA $^{\text {a }}$} \\
\hline \multirow{3}{*}{ Model } & & Sum of Squares & $d f$ & Mean Square & F & Sig. \\
\hline \multirow{3}{*}{1} & Regression & 31.249 & 5 & 6.250 & 21.18 & $0.000^{\mathrm{b}}$ \\
\cline { 2 - 8 } & Residual & 54.864 & 186 & 0.295 & & \\
\cline { 2 - 7 } & Total & 86.113 & 191 & & & \\
\hline
\end{tabular}

a. Dependent Variable: Adoption of DLT

b. Predictors: (Constant), TMS, UA, PU, PEOU, and ICT Infrastructure.

Table 4. Coefficient values

\begin{tabular}{|c|c|c|c|c|c|c|}
\hline \multicolumn{7}{|c|}{ Coefficients $^{\mathrm{a}}$} \\
\hline & \multirow[t]{2}{*}{ Model } & \multicolumn{2}{|c|}{$\begin{array}{c}\text { Unstandardized Coeffi- } \\
\text { cients }\end{array}$} & \multirow{2}{*}{$\begin{array}{c}\text { Standardized } \\
\text { Coefficients }\end{array}$} & \multirow[t]{2}{*}{$\mathbf{t}$} & \multirow[t]{2}{*}{ Sig. } \\
\hline & & $\boldsymbol{B}$ & Std. Error & & & \\
\hline \multirow{6}{*}{1} & (Constant) & 1.207 & 0.306 & & 3.940 & 0.000 \\
\hline & UA & -0.112 & 0.070 & -0.119 & -1.595 & 0.112 \\
\hline & PU & 0.146 & 0.079 & 0.134 & 1.855 & 0.065 \\
\hline & PEOU & 0.004 & 0.070 & 0.003 & 0.051 & 0.960 \\
\hline & ICT Infrastructure & 0.267 & 0.082 & 0.242 & 3.271 & 0.001 \\
\hline & TMS & 0.411 & 0.066 & 0.442 & 6.228 & 0.000 \\
\hline
\end{tabular}

a. Dependent Variable: Adoption of DLT 


\subsection{Analyzing mediating effects}

To analyze the mediating effects of the observed variables (i.e., user awareness of the importance of the DLT, perceived usefulness, perceived ease of use, and information technology infrastructure), we began by modeling the simple effect of each independently observed variable on the dependent variable (i.e., the successful adoption of the DLT).

On the basis of the regression weights of the investigated variables (Table 5), top management support was identified as a mediating variable in the relationships among perceived usefulness, perceived ease of use, user awareness of decision support system importance, and the successful adoption of the DLT. The mediator variable (i.e., top management support) was input to a model for path analysis.

Table 5. Coefficient Regression weights

\begin{tabular}{|l|l|l|c|c|c|}
\hline & & & Estimate & S.E. & P \\
\hline TMS & $<---$ & PEOU & 0.272 & 0.073 & $* * *$ \\
\hline TMS & $<---$ & PU & 0.329 & 0.082 & $* * *$ \\
\hline TMS & $<---$ & UA & 0.228 & 0.069 & .001 \\
\hline DLT & $<---$ & ICT Infrastructure & 0.255 & 0.068 & $* * *$ \\
\hline DLT & $<---$ & TMS & 0.428 & 0.058 & $* * *$ \\
\hline
\end{tabular}

\subsection{Model fit and path analysis}

We used a model to map the relationship between variables and test the fit of a hypothetical model to the empirical data. The path analysis technique was used to test pathways through which variables affect each other and test the validity of the model (i.e., fitting), as shown in Figure 1.

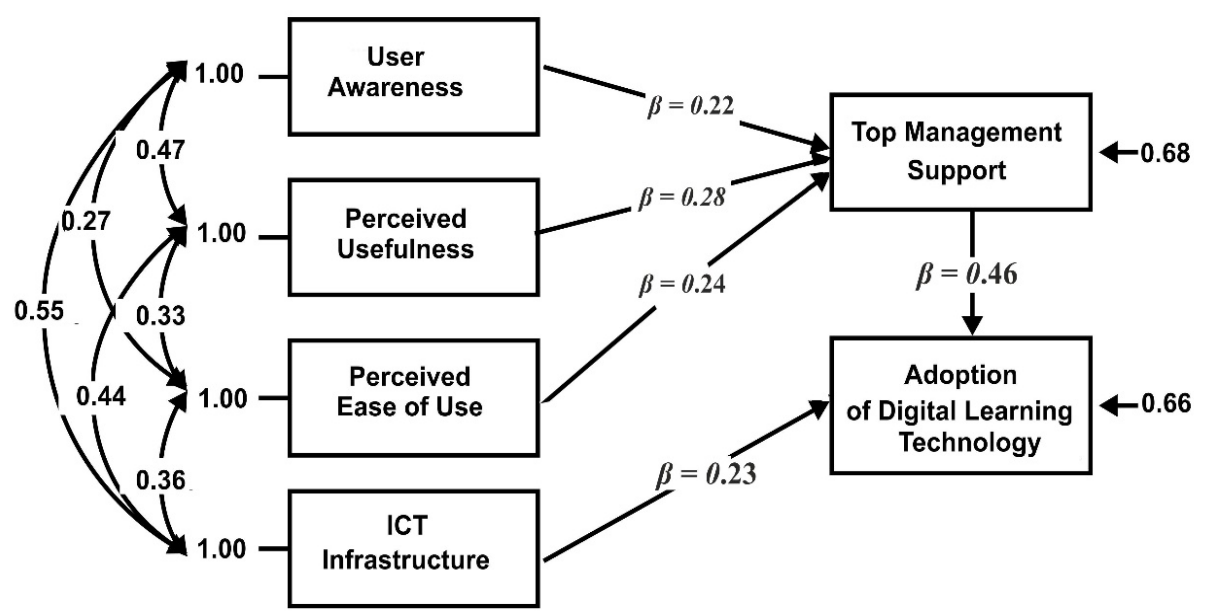

Chi-square $=5.88, \quad$ df $=4$, P-value $=0.20826, \quad$ RMSEA $=0.050$

Fig. 1. Path model 
Although there is some disagreement over which specific tests are "best," it is commonly recommended that researchers examine more than one fit statistic when evaluating model fit [24]. For example, $X^{2}$, Goodness of Fit Index (GFI), and Normed Fit Index (NFI) or Comparative Fit Index (CFI), NNFI, and SRMR tests have been recommended by McDonald and Ho [24]. CMIN is a Chi-square statistic that compares the tested model and the independent model to the saturated model [25]. The overall fit of the model was assessed using the chi-square test fit indexes. Here, chisquare $=5.88$, degrees of freedom $\mathrm{df}=4$, and the probability level $\mathrm{p}$-value $=0.21$. The Root Mean Square Residual (RMR) is the square root of the difference between the residuals of the sample covariance matrix and the hypothesized covariance model [25]. The RMR for our model was 0.010 (note that smaller values are better). The GFI indicates the proportion of variance in the sample variance-covariance matrix that is accounted for by the model. Here, values that are 0.99 or higher indicate well-fitting models [25]. The GFI for our model was 1.00. The Adjusted Goodness of Fit Index (AGFI) is an alternative GFI index in which the value of the index is adjusted relative to the number of model parameters. AGFI values close to the GFI value indicate wellfitting models [25]. The AGFI for our model was 0.95. The NFI assesses a model by comparing the $\chi^{2}$ value of a model to the $\chi^{2}$ value of a null model, and values of 0.9 or higher indicate a good fit [25]. The NFI for our model was 0.99 . The CFI is a revised form of the NFI that considers sample size. Note that values closer to 1.0 indicate a good fit [25]. The CFI for our model was 1.000. The Root Mean Square Error of Approximation (RMSEA) estimates a lack of fit compared to a saturated model. RMSEA values in the range 0.08 to 0.10 indicate a mediocre fit, and values less than 0.08 indicate a good fit. The RMSEA for our model was 0.050 . Model fit is indexes summarized in Table 6.

Table 6. The summarized model fit indexes

\begin{tabular}{|l|c|c|c|}
\hline \multicolumn{1}{|c|}{ Fitness index } & Value & Acceptance Value & Acceptability \\
\hline Chi-square fit & 5.88 & Less is better & Accepted \\
\hline Goodness of fit index (GFI) & 1.00 & Greater than 0.9 & Accepted \\
\hline Adjusted good of fit index (AGFI) & 0.95 & Greater than 0.9 & Accepted \\
\hline Root-mean-square residual (RMR) & 0.010 & Smaller is better & Accepted \\
\hline Relative fit index (RFI) & 0.95 & Greater than 0.9 & Accepted \\
\hline Normed fit index (NFI) & 0.99 & Greater than 0.9 & Accepted \\
\hline Incremental fit index (IFI) & 1.00 & Greater than 0.9 & Accepted \\
\hline Comparative fit index (CFI) & 1.00 & Greater than 0.9 & Accepted \\
\hline $\begin{array}{l}\text { Root-mean-square error of approxima- } \\
\text { tion (RMSEA) }\end{array}$ & 0.050 & Less than 0.08 & Accepted \\
\hline
\end{tabular}

\subsection{Hypothesis testing}

Structural equation modeling was used to analyze the hypothesized direct relationships of six variables considered in this study. The results (Table 7) indicate that there is a positive significant relation and link between TMS and PU $(\beta=0.28, \mathrm{t}=4.023$, $\mathrm{p}=<0.000)$, TMS and PEOU $(\beta=0.24, \mathrm{t}=3.709, \mathrm{p}=<0.000)$, TMS and UA $(\beta=0.22$, 
$\mathrm{t}=3.282, \mathrm{p}=<0.001)$, and TMS and the adoption of a DLT $(\beta=0.46, \mathrm{t}=7.423$, $\mathrm{p}=<0.000)$. In addition, the link between ICT Infrastructure and DLT adoption was positive and significant $(\beta=0.23, \mathrm{t}=3.727, \mathrm{p}=<0.000)$. Moreover, the results explicitly demonstrate that the strongest positive link was between TMS and the adoption of a DLT. Therefore, hypotheses $\mathrm{H}_{1}$ through $\mathrm{H}_{5}$ were proved.

Table 7. Hypotheses testing

\begin{tabular}{|l|l|l|c|c|c|c|}
\hline & & & $\boldsymbol{\beta}$ & S.E. & t & P \\
\hline TMS & $<---$ & PU & 0.28 & 0.082 & 4.023 & $* * *$ \\
\hline TMS & $<---$ & PEOU & 0.24 & 0.073 & 3.709 & $* * *$ \\
\hline TMS & $<---$ & UA & 0.22 & 0.069 & 3.282 & .001 \\
\hline DLT & $<---$ & TMS & 0.46 & 0.058 & 7.423 & $* * *$ \\
\hline DLT & $<---$ & ICT Infrastructure & 0.23 & 0.068 & 3.727 & $* * *$ \\
\hline
\end{tabular}

The path model and hypothesis testing revealed that user awareness, perceived usefulness, and perceived ease of use had a positive significant indirect effect on successful adoption of the DLT through their impact on top management support. However, information technology infrastructure showed a positive significant direct effect on the successful adoption of the DLT. These findings show that top management support has a positive direct effect on the successful adoption of the DLT, which is consistent with the findings of a previous study [20]. The findings relative to the impact of user awareness on the successful adoption of the DLT are consistent with the findings of other previous studies [19]. We found that perceived usefulness and perceived ease of use have a positive indirect effect on the successful adoption of the DLT, which is also consistent with the findings of previous studies [9], [15], [21]. However, this contrasts with the findings of Akinnuwesi et al. [19], who revealed that perceived usefulness has no impact on the intent to adopt the biometric technology. The results of this study indicate that information technology infrastructures have a positive direct effect on the successful adoption of DLT.

\section{Conclusions}

This study has outlined the impact of a set of factors influencing the successful adoption of DLT in developing countries. By understanding the influence of these factors, managers can formulate effective schemes to implement and use technology and increase the usage of a DLT. Based on the model fit indexes, we consider that our findings will be of value to top-level managers and may help decision makers avoid DLT failures by understanding the factors that affect the adoption and usage of technology, the relations between these factors, and how these factors can be measured. In addition, our findings may help institutions predict user awareness and technology acceptance prior to investing in technology and predict whether the investment will be accepted and used. For such a system to be successful, a proper ICT infrastructure must be developed to facilitate smooth adoption and implementation processes. The findings of this study could contribute to theoretical modeling by giving new insights into the theory and modifying the DLT adoption theories. This study has provided 
important insights into understanding information technology/system adoption and utilization in public institutions in developing countries. This study also provides a guideline for an institution's management to encourage the use of new DLTs. This study proposed to improve a successful adoption and utilization of the particular educational services that are supported by adopting new technologies by deepening the knowledge about factors influencing or facilitating their adoption and utilization for developing nation in general, and for the Libyan country in particular.

\section{Research limitations and future work}

The study targeted only government institutions. However, the impact of organizational aspects on the adoption of DLT could differ in non-government institutions. In addition, our data were collected from a single country, and the impact of considered factors on the adoption of DLT can differ among developing countries.

An additional investigation could be conducted to determine the moderating and mediating effects among other elements, such as task characteristics, cultural characteristics, environmental characteristics, internal and external end-user training, and technology acceptance factors. In addition, future research could effectively employ different methodologies, such as focus groups, interviews, and longitudinal studies, to examine factors that influence the adoption and utilization of DLT.

\section{$7 \quad$ References}

[1] Tarus, J. K., Gichoya, D., \& Muumbo, A. (2015). Challenges of implementing e-learning in Kenya: A case of Kenyan public universities. The International Review of Research in Open and Distributed Learning, 16(1).

[2] Hubbard, P. (2017). Technologies for teaching and learning L2 listening. The Handbook of Technology and Second Language Teaching and Learning, 93-106. http://dx.doi.org/10.1002/9781118914069.ch7

[3] Chan, B. S., Churchill, D., \& Chiu, T. K. (2017). Digital Literacy Learning In Higher Education Through Digital Storytelling Approach. Journal of International Education Research (JIER), 13(1), 1-16. http://dx.doi.org/10.19030/jier.v13i1.9907

[4] Kocdar, S. (2017). Designing Teaching and Learning for a Digital Age. The International Review of Research in Open and Distributed Learning, 18(3). https://opentextbc.ca/teachinginadigitalage/

[5] Passey, D., Laferrière, T., Ahmad, M. Y. A., Bhowmik, M., Gross, D., Price, J., ... \& Shonfeld, M. (2016). Educational digital technologies in developing countries challenge third party providers. Journal of Educational Technology \& Society, 19(3), 121. http://www.jstor.org/stable/jeductechsoci.19.3.121

[6] Al-Gahtani, S. S. (2016). Empirical investigation of e-learning acceptance and assimilation: A structural equation model. Applied Computing and Informatics, 12(1), 27-50. https://doi.org/10.1016/j.aci.2014.09.001

[7] Ragu-Nathan, B. S., Apigian, C.H., Ragu-Nathan, T. S. and Tu, Q. (2004). "A path analytic study of the effect of top management support for information systems performance." Omega 32, 459-471. http://dx.doi.org/10.1016/j.omega.2004.03.001 
Paper-Analysis Approach to Identify Factors Influence Digital Learning Technology Adoption and ...

[8] Loonam, J., McDonagh, J., Kumar, V., \& O'Regan, N. (2014). Top Managers and Information Systems:'Crossing the rubicon!'. Strategic Change, 23(3-4), 205-224. http://dx.doi.org/10.1002/jsc.1971

[9] Elzawi, A., \& Wade, S. (2012). Barriers to ICT adoption in quality of engineering research in Libya: how to bridge the digital divide? University of Huddersfield. http://eprints.hud.ac.uk/13458/

[10] Stroud, R., Drayton, B., Hobbs, K., \& Falk, J. (2015). Interactive Whiteboard Use in HighTech Science Classrooms: Patterns of Integration. International Journal of Emerging Technologies in Learning, 10. http://dx.doi.org/10.3991/ijet.v9i9.4141

[11] Abrami, P. C., Wade, C. A., Lysenko, L., Marsh, J., \& Gioko, A. (2016). Using educational technology to develop early literacy skills in Sub-Saharan Africa. Education and Information Technologies, 21(4), 945-964. https://doi.org/10.1007/s10639-014-9362-4

[12] Raso, D., Tungkunanan, P., \& Anukulwech, A. (2017). Factors Supporting an Information Technology Management: Teachers in Primary Schools in Thailand. International Journal of Emerging Technologies in Learning, 12(4). https://doi.org/10.3991/ijet.v12i04.6654

[13] Davis, F. D. (1989). "Perceived usefulness, perceived ease of use, and user acceptance of information technology.” MIS quarterly, 319-340. http://dx.doi.org/10.2307/249008.

[14] Redfern, J., Santo, K., Coorey, G., Thakkar, J., Hackett, M., Thiagalingam, A., \& Chow, C. K. (2016). Factors Influencing Engagement, Perceived Usefulness and Behavioral Mechanisms Associated with a Text Message Support Program. PloS one, 11(10), e0163929. https://doi.org/10.1371/journal.pone.0163929

[15] Khan, M., Hossain, S., Hasan, M., \& Clement, C. K. (2012). Barriers to the introduction of ICT into education in developing countries: The example of Bangladesh. Online Submission, 5(2), 61-80.

[16] Rai, A., Patnayakuni, R., \& Seth, N. (2006). Firm performance impacts of digitally enabled supply chain integration capabilities. MIS quarterly, 225-246.

[17] Mahenge, M. P., \& Sanga, C. (2016). ICT for e-learning in three higher education institutions in Tanzania. Knowledge Management \& E-Learning: An International Journal (KM\&EL), 8(1), 200-212.

[18] Rhema, A., \& Miliszewska, I. (2014). Analysis of student attitudes towards e-learning: The case of engineering students in Libya. Issues in Informing Science and Information Technology, 11, 169-190. Retrieved from http://iisit.org/Vol11/IISITv11p169190Rhema0471.pdf

[19] Akinnuwesi, B. A., Uzoka, F. M. E., Okwundu, O. S. and Fashoto, G. (2016). "Exploring biometric technology adoption in a developing country context using the modified UTAUT." International Journal of Business Information Systems, 23, 482-521. http://dx.doi.org/10.1504/IJBIS.2016.080219.

[20] Ali, M., Zhou, L., Miller, L. and Ieromonachou, P. (2016). "User resistance in IT: A literature review." International Journal of Information Management, 36, 35-43. http://dx.doi.org/10.1016/j.ijinfomgt.2015.09.007.

[21] Sife, A., Lwoga, E., \& Sanga, C. (2007). New technologies for teaching and learning: Challenges for higher learning institutions in developing countries. International journal of education and development using ICT, 3(2).

[22] Devitt, J. H., Kurrek, M. M., Cohen, M. M., Fish, K., Fish, P., Noel, A. G., \& Szalai, J. P. (1998). Testing internal consistency and construct validity during evaluation of performance in a patient simulator. Anesthesia \& Analgesia, 86(6), 1160-1164. http://dx.doi.org/10.1213/00000539-199806000-00004

[23] Alin, A. (2010). "Multicollinearity." Wiley Interdisciplinary Reviews: Computational Statistics, 2, 370-374. http://dx.doi.org/10.1002/wics.84. 
Paper-Analysis Approach to Identify Factors Influence Digital Learning Technology Adoption and ...

[24] McDonald, R.P. and Ho, M. H. R. (2002). "Principles and practice in reporting structural equation analyses." Psychological methods, 7, 64. http://psycnet.apa.org/doi/10.1037/1082-989X.7.1.64.

[25] Barrett, P. (2007). "Structural equation modelling: Adjudging model fit." Personality and Individual differences, 42, 815-824. http://dx.doi.org/10.1016/j.paid.2006.09.018.

\section{Authors}

Abubaker Kashada was born in Zawia, Libya in 1966. He received the Master's degree in Information and Communications Technology for Engineering ICTE in 2003 from Coventry University, UK. At present, he is a postgraduate student of information science and technology at Beijing University of Chemical Technology. His current research interests include IT infrastructure, Information and Communication Technology, Internet Technologies, Educational Technology. (e-mail: 2012420020@mail.buct.edu.cn).

Hongguang Li was born in Liaoning Province, P. R. China in 1963. He received the Ph. D. degree in East China University of Science and Technology in 2004. At present, he is professor in Beijing University of Chemical Technology. His research interests are Modeling, control and optimization of chemical process as well as computer based intelligent control for industrial. (e-mail: lihg@mail.buct.edu.cn).

Osama Koshadh was born on 1977, in Tripoli, Libya. He obtained his MSc in management at Coventry University England. He is currently a university Teaching staff at the Business Management Department, Al zawia University and he also occupies the Executive Director of the National office for EU programs in education, Libya where he currently is involving in a number of education projects. His current research interests include Electronic learning, Educational Technology. (e-mail: okashadah@yahoo.co.uk).

Article submitted 08 July 2017. Final acceptance 06 February 2018. Final version published as submitted by the authors. 